\title{
Spatiotemporal Variability in Soil Water Content Profiles under Young and Mature Oil Palm Plantations in North Bengkulu Regency
}

\author{
Bandi Hermawan $^{\mathrm{a},}$, Indra Agustian $^{\mathrm{b}}$, Hasanudin $^{\mathrm{a}}$, Reny Herawatic, Bambang Gonggo Murcitro ${ }^{\mathrm{a}}$ \\ ${ }^{a}$ Department of Soil Science, University of Bengkulu, Jl.WR. Supratman, Bengkulu, 38178, Indonesia \\ ${ }^{b}$ Department of Electrical Engineering, University of Bengkulu, Jl. WR. Supratman, Bengkulu, 38178, Indonesia \\ ${ }^{c}$ Department of Agroecotechnology, University of Bengkulu, Jl. WR. Supratman, Bengkulu, 38178, Indonesia
}

Corresponding author: 'bhermawan@unib.ac.id

\begin{abstract}
Soil water content (SWC) profile refers to the vertical distribution of volumetric SWC at a certain depth of soil concerning the plant water availability. The current study aimed to evaluate the vertically spatial distributions and temporal variations in SWC profiles under young and mature oil palm trees during the end period of the rainy season. Twenty couples of sensors were inserted into $5 \mathrm{~cm}$ soil depth intervals up to $100 \mathrm{~cm}$. Each sensor pair was connected to the dielectric instrument to measure the electrical impedance $(Z$, in $\mathrm{k} \Omega)$ at each soil layer. The measured $Z$ was then converted to the gravimetric $S W C\left(\theta \mathrm{g}\right.$, in g. $\left.\mathrm{g}^{-1}\right)$ using an equation of $\theta \mathrm{g}=0.62 . \mathrm{Z}^{-0.2}$ found in our previous study. The gravimetric SWC data were then multiplied by soil bulk density for corresponding layers to get volumetric SWC $\left(\theta_{\mathrm{v}}\right.$, in $\left.\mathrm{cm}^{3} \cdot \mathrm{cm}^{-3}\right)$. Results showed that soil water profiles' depths were 40 to $70 \mathrm{~mm}$ higher under mature than under young oil palm plantations during six weeks of measurements. The vertical distribution of soil bulk density could be why the spatiotemporal variability in water content profile. Looser layers throughout the young oil palm soil profile might cause a higher proportion of drainage pores and result in less water content compared to the denser layers under the mature oil palm.
\end{abstract}

Keywords - electrometer; soil water profiles; temporal variations.

\section{INTRODUCTION}

Soil water content profile, defined as the water volume held in the soil profile in a certain depth of soil, plays essential roles in describing many aspects of plant-soil water relations. Plant evapotranspiration and root water uptake are two relations that can help understand efficient plant water use, soil water storage, and competition in water-related ecosystems [1]. The water profile is usually expressed in units like soil profile depth and shows the proportion of water depth to a total depth of soil profile. Therefore, it determines how much rainfall water falling on the ground remains in the soil matrix at a defined depth when subject to water loss by evapotranspiration and drainage processes. Soil water content profile can explain the plant availability of soil water and calculate how much irrigation water is required when farmers need to adopt precise irrigation techniques and improve water use efficiency and conservation. Determination of water use efficiency and the rate of water loss by evapotranspiration control the crop yields, while total irrigation water may be related to the cost of sustainable crop production [2]. Understanding the soil water content profile plays an essential role in sustainable agriculture practices, particularly concerning soil water management in agricultural sites.

Further analyses on the soil water content profile can detail the relationship between surface soil moisture and the moisture content at the deeper soil layers by considering differences in soil physical characteristics at each layer [3]. Several researchers have emphasized models to convert the time series of surface soil water measurements to a variable capable of predicting soil water dynamics of the lower layers. Matgen et al., for example, have tested the surface and lower soil water content relation using both simulated and measured data to improve understanding of the root-zone soil moisture characteristics following rainfall and runoff events [4]. The relation may explain many aspects of the plant's soil water use and how it can be available during discharged and recharged periods of growing seasons. Other researchers have paid attention to great efforts to find an explanation on the influence of some physical properties, such as structure, climate, and land-use history, in controlling soil hydraulic properties and water dynamics 
using a mathematical model and the field observation [5]. The amount of existing water in the soil profile over time of plant growth can also be controlled by agrometeorological variables near the soil surface, particularly those related to the plant evapotranspiration [6].

Soil water content profile can be determined by measuring gravimetric water content for each soil layer to a defined depth. Determination of gravimetric water can be done directly in the laboratory using the gravimetrical method by calculating water loss when the soil dries out [7]. It can also be obtained indirectly by measuring other variables from which soil water can be calculated. Despite its accuracy and usually used as a standard method, the direct technique can hardly be applied and may raise problems when measuring numerous data of soil water content, such as during periodical monitoring of soil water content in the field. The conventional method's application is also limited when measurements will be taken place in the undisturbed area, such as highly dense cash cropping land. Problems raised from the gravimetric method in soil water content determination can be solved by measuring waterrelated parameters in the field using a simple mathematical model [8]. The parameters should be measurable quickly and instantly to provide real-time soil water content.

Many researchers worldwide have developed several techniques for the field determination of soil water. The need for instant techniques in determining in-situ soil water content has been initiated in the last few decades using radioactive and electrical velocity variables as the soil water predictors [9]. Compared to the conventional direct technique, indirect methods have some advantages because they can instantly collect non-destructive soil water data in the field [10]. Several moisture-related parameters have also been measured elsewhere by other researchers to monitor soil water content profiles covering a large agricultural cultivation area. Neutron probe is a tool that has been widely used to measure in-situ soil water content using radiography properties [11]. The instrument releases fast neutrons to the soil matric; when colliding with hydrogen, they lose much energy. Since water contains two atoms of hydrogen per molecule, the detection of slow neutrons returning to the probe allows a prediction of soil moisture. However, the method is unable to measure soil water content in the smallscale and shallow rooting zone of agricultural practices. Although the radioactive variables can be applied to calculate landscape-scale soil water content precisely, they can be harmful to the operator, mainly when used to measure soil water content close to the soil surface [12].

Time Domain Reflectometry (TDR) is another instrument widely used for soil water content determination in the field without using any laboratory works. The instrument is an electronic device used to determine the characteristics of electrical lines in the soil by observing reflected waveforms. It applies the travel time of voltage pulse and a parallel transmission probe inserted into the soil profile to a certain depth [13]. When the electrical current travels through a soil column, the presence of opposition characteristics to the current in the soil column, such as the soil, water, and gas composition, will decrease voltage amplitude across the column for a given current. However, this instrument is costly and not suitable for small-scale farmers. Therefore, a user-friendly and cheap device applying other water-related dielectric variables is needed to quickly determine real-time soil water content in the field at an affordable cost [14].

Oil palm (Elaeis guineensis Jacq) is a tropical tree crop that becomes a significant income for farmers in tropical countries. The crop should be grown in deep and welldrained soils and requires a high year-round rainfall with a short dry season to get optimum growth and production. Monthly yields in fresh fruit bunch are positively correlated with soil water balance; a lack of soil water content profiles may cause a less significant plant response to nutrient addition [15]. This is because water functions as a dissolving agent and transmitting media of nutrients when absorbed by plant roots.

Water balance under oil palm plantations depends on soil layers' properties, especially those responsible for soil water holding capacities such as texture and organic matter. Understanding the distribution of soil layer characteristics and their relation to water balance may help us estimate root water uptake and water stress response by oil palm [16]. Limited information in soil water balance may result in uncertain crop production, particularly during discharged periods of dry seasons. Farmers usually find the seasonal fluctuation in oil palm production due following the net of soil water balance, in which the lowest production occurs about six three months after the end of the dry period.

It can be summarized that the existing water in the soil profiles controls the growth and productivity of crops. Therefore, this study aimed to evaluate spatiotemporal variability in soil water content profiles under the three-year and twenty-year oil palm plantations. Long-term production of oil palm could probably have resulted in different soil layer characteristics, therefore, leading to different temporal variability in soil water content compared to a newly established plantation.

\section{MAterials AND MethoD}

\section{A. Profile Description and Instrument Calibration}

The study was conducted during a water-discharged May and June 2019 at two oil palm sites in North Bengkulu Regency, Bengkulu Province, Indonesia. The study sites were about 20 to $50 \mathrm{~km}$ from the capital of the province. Two soil profiles were described at three-years and twentyyears oil palm plantations, respectively, to determine the boundary and characteristics of soil horizons up to the depth of $100 \mathrm{~cm}$. The young plantation occupied Inceptisols and was located $500 \mathrm{~m}$ above sea level (102 $12^{\prime} 02.1^{\prime \prime} \mathrm{E}$; $\left.03^{0} 27^{\prime} 34.6^{\prime \prime} \mathrm{S}\right)$. On the other hand, the mature plantation was established in Ultisols and located at about $25 \mathrm{~m}$ above sea level (102009'55.0" E; 03036'30.5” S).

Ten undisturbed and disturbed soil samples were collected from each site at $10 \mathrm{~cm}$ depth intervals for the laboratory analyses. Undisturbed and disturbed soil samples were taken from the pit that has been used for profile description. There were 50 undisturbed core and disturbed soil samples taken from both sites in this study. Undisturbed samples were taken using the stainless cylinder of $4-\mathrm{cm}$ height and 7-cm wide and analyzed soil bulk density, moisture characteristics, and pore-size distribution. Disturbed soil samples were analyzed to determine the field 
water content at the time of measurements, texture, and organic carbon content.

Simultaneously with soil sampling, twenty couples of 5$\mathrm{cm}$ sensor wires were inserted into the $5 \mathrm{~cm}$ soil intervals up to the depth of $100 \mathrm{~cm}$. The sensors were inserted in such a way; therefore, the uncovered wires made good contact with soil. The lowest $5-\mathrm{cm}$ parts of wires were left uncovered with rubber to allow electrical impedance readings at corresponding soil depth. The dielectric instrument was then connected to the sensor's upper parts to measure the electrical impedance of defined soil layers (Figure 1). The instrument submitted the electric current to the defined soil depth; the soil's electrical impedance was recorded. Description of a dielectric instrument used in this study has been reported earlier [17].
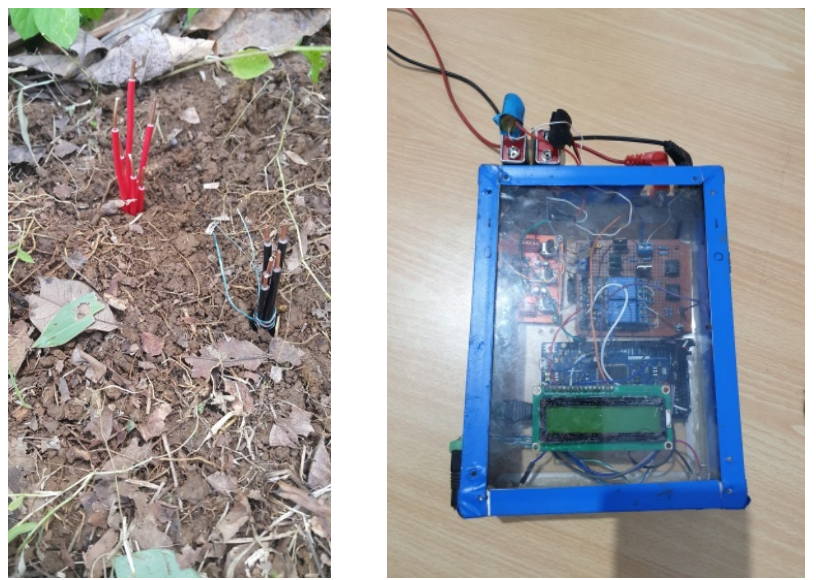

Fig. 1 Sensor probes inserted to soil profile (left) and electrometer for the impedance measurements (right).

The measured impedance values $(Z$ in $k \Omega$ ) were then converted to gravimetric soil water content $\left(\theta_{\mathrm{g}}\right.$ in $\left.\mathrm{g} . \mathrm{g}^{-1}\right)$ using a nonlinear model of:

$$
\theta_{\mathrm{g}}=\mathrm{a} \cdot \mathrm{Z}^{\mathrm{b}}
$$

Constants $\mathrm{a}$ and $\mathrm{b}$ were obtained by regressing $\theta$ values from the laboratory analyses to the field measured $\mathrm{Z}$ values for each corresponding depth. As shown in Figure 2, instrument calibration resulted in a and $\mathrm{b}$ values of about 0.62 and -0.2 , respectively. Equation 1 was then written as:

$$
\theta_{\mathrm{g}}=0.62 . \mathrm{Z}^{-0.2}
$$

The $\theta_{\mathrm{g}}$ values were multiplied by bulk density at the corresponding layer to get volumetric water $\left(\theta_{\mathrm{v}}\right.$ in $\left.\mathrm{cm}^{3} \cdot \mathrm{cm}^{-3}\right)$.

\section{B. Spatiotemporal Soil Water Measurements}

Gravimetric soil water content was determined using the indirect method by measuring the electrical impedance $(Z)$ in the field. The $Z$ values were measured twice a week during a rainy period of May to June and once a week at the end of the rainy season (June to July) of 2019 using the electrometer. Before the field measurements, the instrument was calibrated by exposing sensors to the air and water. When calibrated $Z$ values close to those for the air and water, measurements were then taken in the $5 \mathrm{~cm}$ intervals to the depth of $100 \mathrm{~cm}$. Therefore, $20 \mathrm{Z}$ data were recorded per site. It needed only about two minutes to read and record twenty $\mathrm{Z}$ data for each study site. Meteorological data, including daily rainfall and air temperature, were obtained from the nearest local weather station in each study site. The measured $\mathrm{Z}$ variables were then converted to $\theta_{\mathrm{g}}$ values using Equation 2.

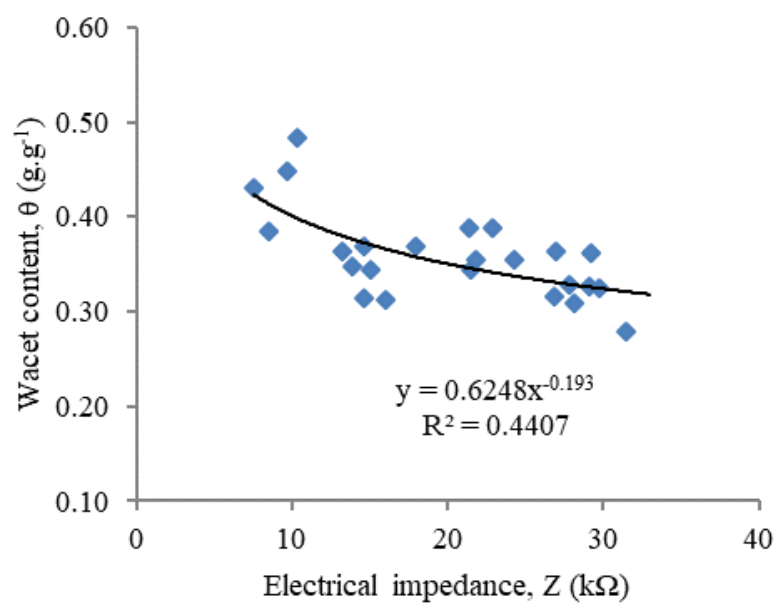

Fig. 2 Constants $\mathrm{a}$ and $\mathrm{b}$ of Equation 1 as resulting from the calibration of the dielectric instrument.

For each study site, the predicted values of gravimetric soil water content $\left(\theta_{\mathrm{g}}\right)$ at $0-5$ and $5-10 \mathrm{~cm}$ depths were averaged then multiplied by the bulk density value at the 0 $10 \mathrm{~cm}$ soil layer to provide the volumetric water content $\left(\theta_{\mathrm{v}}\right)$ at $0-10 \mathrm{~cm}$ soil depth. The above conversion of $\theta_{\mathrm{g}}$ to $\theta_{\mathrm{v}}$ was repeated for the next $10 \mathrm{~cm}$ soil thickness up to $100 \mathrm{~cm}$. The use of volumetric instead of gravimetric water content profiles was preferable because the volumetric variables can be converted to the soil water depths and may explain the behavior of other related parameters such as rainfall, evapotranspiration, and plant water use. Volumetric soil water content can also be applied to automatically identify the soil water cycle and leverage dynamics in the irrigation management system [18].

\section{RESULTS AND DISCUSSION}

\section{A. Soil Profile Description}

Results of visual observations on soil profiles at threeand twenty-years-old oil palm were presented in Figure 3. A and $\mathrm{Bt}$ Horizons occupied the 0-10 and 10-60 cm depths at the young plantation site and $0-21$ and $21-56 \mathrm{~cm}$ depths at the mature site, respectively. Boundary and thicknesses of both horizons were significantly different between the two study sites. The A Horizons at the young plant site consisted of 0-6 cm black (A1) and 6-10 cm yellowish-brown layers (A2), while at the mature site of $0-12 \mathrm{~cm}$ dark brown (A1) and 12-21 cm yellowish-brown soils (A2). Less developed A Horizons at the 3-years oil palm site could be related to a lack of additional organic matter, particularly from the young trees' dying roots. Deeper layers were characterized by brownish to dark brown layers for the young plantation and reddish yellow Bt Horizons for the mature oil palm, respectively.

The characteristics of soil profiles at the two sites were also different in terms of structure, texture, and consistency. The young plantation site was dominated by angular blocky 
structure up to the depth of $60 \mathrm{~cm}$, while the mature oil palm site by granule at the topsoil and angular blocky structures at the subsoil. Variations in topsoil structure were probably due to different land covers between the two study sites. Granule topsoil structure found under 20 years of oil palm oil could be formed by long-term biological activities such as rootlength density that filled soil bio pores [19]. As shown in Figure 3, oil palm roots distributed well to the depth of 56 $\mathrm{cm}$ at the mature oil palm plantation site in comparison to only $30 \mathrm{~cm}$ at the young oil palm. On the other hand, the destruction of topsoil aggregates by rainfall under less protection and low organic matter content at the soil surface could result in blocky shapes of topsoil structure under the young site. The three-year oil palm trees provided about $6 \mathrm{~m}$ gaps and left surface soils unprotected during the rainy seasons.
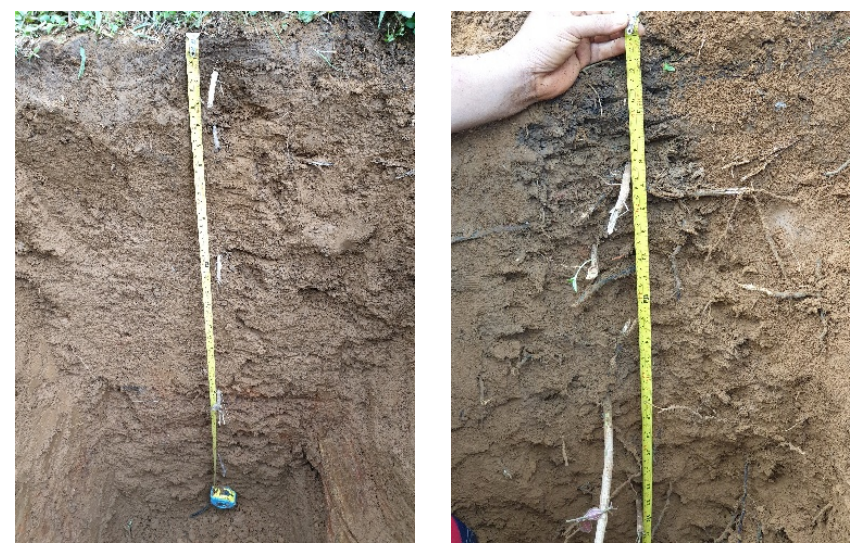

Fig. 3 The soil profiles for young (left) and mature oil palm plantations (right).

TABLE I

SOIL TEXTURE, ORgANic CARBON AND BULK DENSITY OF STUDY SOIL PROFILES

\begin{tabular}{cccc}
\hline $\begin{array}{c}\text { Soil Depth } \\
(\mathbf{c m})\end{array}$ & Texture & $\begin{array}{c}\text { C-org } \\
\mathbf{( \% )}\end{array}$ & $\begin{array}{c}\text { Bulk Density } \\
(\mathbf{g . c m})\end{array}$ \\
\hline & Three-Years & Plantation \\
$0-10$ & Sandy loam & 5.64 & 0.87 \\
$10-20$ & Sandy loam & 4,19 & 0.71 \\
$20-30$ & Sand & 4,20 & 0.80 \\
$30-40$ & Sand & 3.09 & 0.68 \\
$40-50$ & Sand & 2.96 & 0.68 \\
$50-60$ & Sand & 3.01 & 0.83 \\
$60-70$ & Sand & 2.69 & 0.86 \\
$70-80$ & Sandy loam & 2.21 & 0.91 \\
$80-90$ & Sandy loam & 2.20 & 0.91 \\
$90-100$ & Sandy loam & 2.28 & 1.06 \\
& Twenty-Years & Plantation & \\
$0-10$ & Clay & 3.87 & 0.86 \\
$10-20$ & Clay & 2.88 & 1.12 \\
$20-30$ & Clay & 2.23 & 1.02 \\
$30-40$ & Clay & 2.57 & 1.07 \\
$40-50$ & Clay & 2.20 & 0.99 \\
$50-60$ & Clay & 2.01 & 1.08 \\
$60-70$ & Clay & 1.81 & 1.03 \\
$70-80$ & Clay & 1.95 & 0.88 \\
$80-90$ & Clay & 1.96 & 1.18 \\
$90-100$ & Clay & 1.72 & 1.00 \\
\hline
\end{tabular}

Laboratory analyses on basic characteristics of soil profiles are presented in Table 1. Soil profiles at the young oil palm site were looser than at the mature site in most soil layers. Soil bulk density values at the three-years plantation were less than $1.0 \mathrm{~g} . \mathrm{cm}^{-3}$ up to the depth of $90 \mathrm{~cm}$, while at the 20 -years site were above $1.0 \mathrm{~g} . \mathrm{cm}^{-3}$ for seven out of ten observed layers. Compared to the mature oil palm site, lower bulk density values at the young oil palm soils were due to coarser texture classes and higher soil organic carbon levels.

The dependence of soil bulk density values on the particle-size distribution has been reported elsewhere, and the study used soil texture for the online prediction of soil compaction status [20]. Fine texture layers of soil under the mature plantation might cause the particles to be closer to each other, resulting in higher bulk density values than the coarse soil under the young plantation. Trends of texture, organic carbon, and bulk density differences between to sites were spatially consistent throughout the depth of $0-100 \mathrm{~cm}$. However, the texture might not be the main reason for soil compaction differences at the $0-100 \mathrm{~cm}$ profiles between young and mature plantations. The research reported by Pöhlitz et al. [21] indicated no significant differences in mechanically-induced compaction of soils with different texture classes when the soil water content was about near the field capacity.

On the other hand, organic carbon fraction could be a more sensitive parameter in terms of reduced soil bulk density because of its lower particle density values than mineral fractions. Variations in soil organic carbon could be related to differences in parent materials during soil formation or management systems applied to the soil. For example, the application of swine manure and poultry litter doses of up to $480 \mathrm{~m}^{3}$ and $18 \mathrm{Mg} \mathrm{ha}^{-1}$ year $^{-1}$, respectively, significantly increased soil organic carbon followed by decreased soil density [22]. Decreases in soil bulk density would increase total porosity and macropores' proportion for the young plantation soil.

\section{B. Soil Electrical Impedance Profiles}

Electrical impedance is an extended Ohm's Law to cover alternate current (AC) circuits and functioned as a replacement of electrical resistance [23]. In the current study, the electrical impedance was performed as a predicting parameter for real-time soil water content in the gravimetric terminology. Temporal variability in the soil electrical impedance during 24 days of measurements was more pronounced at the $0-40 \mathrm{~cm}$ depth of three-years plantation, while significant variability at the mature oil palm site occurred at deeper layers of 50-70 cm (Figure 4). The highest temporal variability in electrical impedance for the younger plants ranged from 5 to $40 \mathrm{k} \Omega$ at the uppermost $0-5$ $\mathrm{cm}$ soil layer, during the most variable impedance for the mature location from 20 to $65 \mathrm{k} \Omega$ at the $55-60 \mathrm{~cm}$ soil depth. The temporal variations indicated that electrical impedance changed quickly at the surface soil under the three-year oil palm and at the deeper layers under the mature plantation.

Results suggested that both study soils had different vertically spatial characteristics to transmit the electrical current when subject to weather changes above the soil surface. Less covered surface soil at the young oil palm site seemed to be more sensitive to daily changes in the dielectric properties than fully covered soil at the mature location. In the mature oil palm soil, daily weather conditions were probably intercepted by dense plant 
canopies, therefore, had fewer effects on temporal variability in the electrical impedance. The temporal variability in soil electrical impedance was also affected by the size distribution of soil pores since soils' ability to transmit the electrical current was pore-solid phase-dependent. Total and size-distribution of soil pores might be evaluated from bulk density data. Low soil bulk density at the near-surface of young plantation soil had left the layers more porous and responded more quickly to any changes in the composition of water and air in the pores.
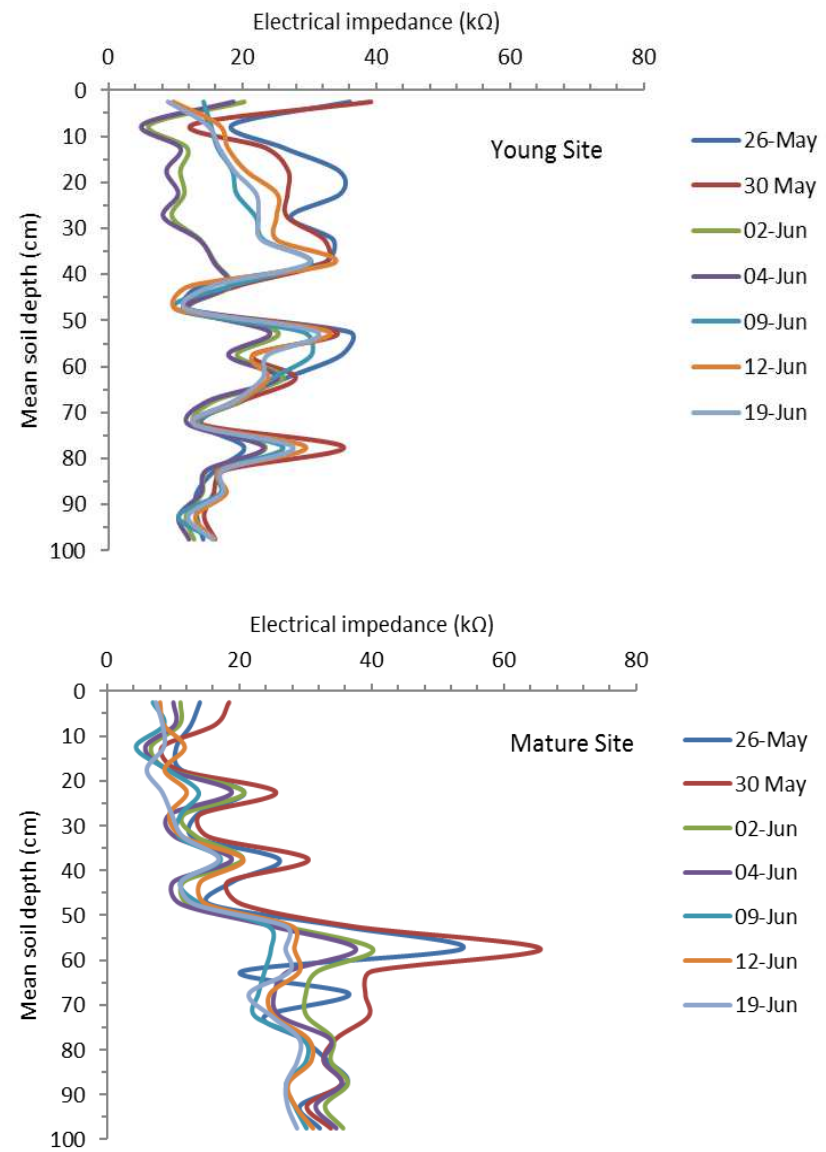

Fig. 4 The spatiotemporal variability in soil electrical impedance at different oil palm sites during 24-days of measurements.

Time-dependent changes in dielectric properties at the 50$70 \mathrm{~cm}$ soil depth were probably due to characteristics of solid-liquid-gaseous phases in the soil profile controlling the conductance of electrical current as reported by other researchers. The electrical current could travel faster with less resistivity through liquid than two other soil phases. However, the electrical conductance in a liquid phase is influenced by the liquid's temperature and solvent [24]. The liquid temperature may expand the intermolecular arrangement of liquid and reduce the electrical conductance. Variations in soil's liquid temperature may explain the diurnal and seasonal variability in electrical conductance and other related soil characteristics [25].

Although the prediction results might be influenced by soil temperature at the time of measurements, these findings promote using dielectric properties to determine the realtime soil water content in-situ in the field. Relations between electrical characteristics and soil physical properties could provide beneficial effects on some agricultural practices. Recently, Bertermann and Schwarz have reported the dependence of electrical resistivity on some soil physical properties such as soil compaction and soil wetness over a wide range of soil classes [26]. Dielectric properties of soils have also been used to calculate volumetric water content, ranging from air-dried to saturated conditions, and bulk electrical conductivity [27].

\section{Spatiotemporal Variations in Soil Water Content}

Diurnal and seasonal fluctuation in the electrical impedance could be used to monitor temporal soil wetness in the field. Our previous laboratory study on repacked soils has proven the very close relations between the electrical impedance and water content [28]. The relations between the two variables were very strong and followed a nonlinear regression. Variations in the electrical impedance showed about $90 \%$ of the variations in gravimetric soil water content. A similar approach has also been applied to monitor forest soil properties using soil electrical resistivity [29]. Since the electrical impedance values were recorded very quickly using the dielectric instrument, the collection of soil wetness data could also be taken place just in few seconds.
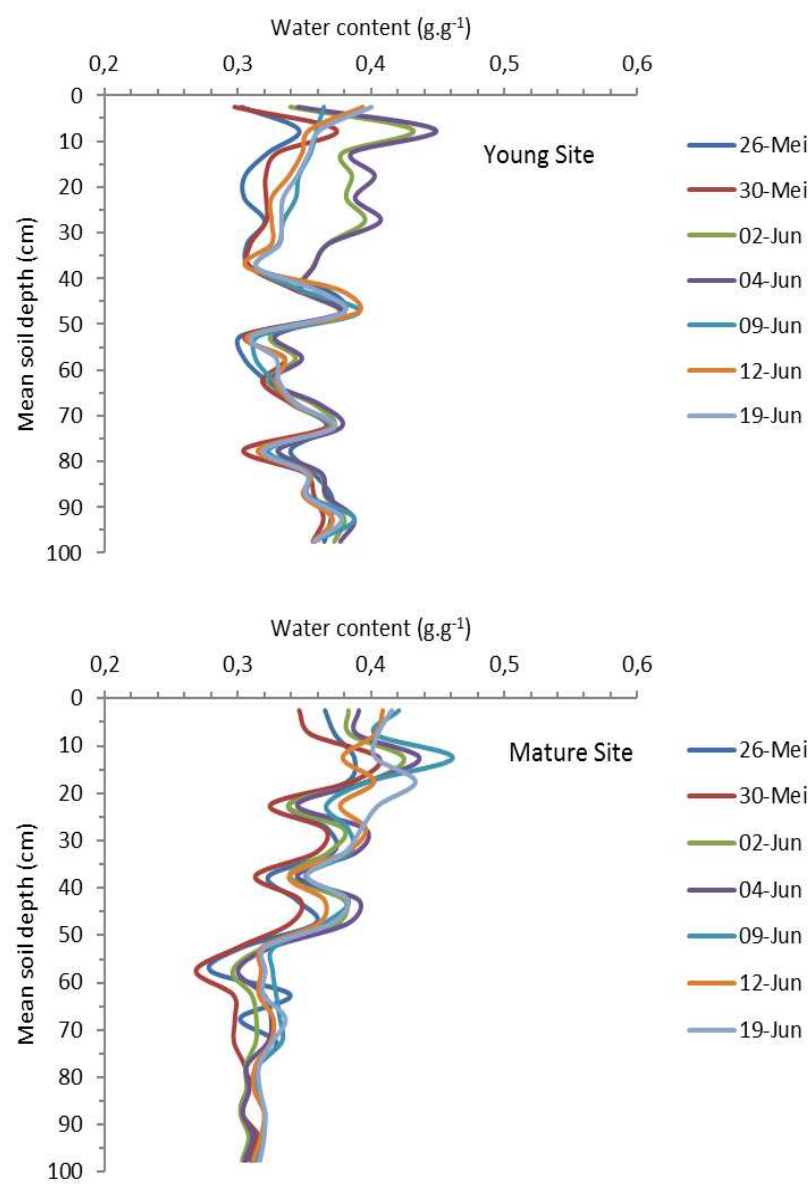

Fig. 5 The spatiotemporal variations in gravimetric soil water content in two study sites as calculated from Equation in Figure 2.

In the current study, the measured electrical impedance data were converted to gravimetric water content using the equation provided in Figure 2, and the results of impedanceto-water conversions were presented in Figure 5. Vertical and temporal variations in gravimetric soil water content 
occurred more pronounced at the $0-40 \mathrm{~cm}$ soil layers compared to a lower depth. Overall, soil water content profiles were more fluctuated with measurements at threeyears oil palm plantation than at older plantation sites. Maximum temporal differences in gravimetric water content were about $0.1 \mathrm{~g} . \mathrm{g}^{-1}$ for the young site and $0.08 \mathrm{~g} . \mathrm{g}^{-1}$ for the mature plant soil. The smallest variations occurred at the depths of $45-50 \mathrm{~cm}$ and $60-100 \mathrm{~cm}$ for the young and 80-100 $\mathrm{cm}$ for the mature oil palm soils. Soils at the A and B horizons seemed to be more sensitive to water loss during a May-to-June discharge period.

In terms of soil water availability to the plant, it was necessary to use the volumetric water content expressing the proportion of water to soil volumes. Volumetric soil water could also be used to calculate soil water balance. Averages of gravimetric soil water content at each $10 \mathrm{~cm}$ layer intervals were multiplied by bulk density at corresponding depths to determine the volumetric water content. The conversion results of gravimetric to volumetric water content depended on the values of bulk density. The more values of bulk density, the higher values of volumetric compared to gravimetric water content.
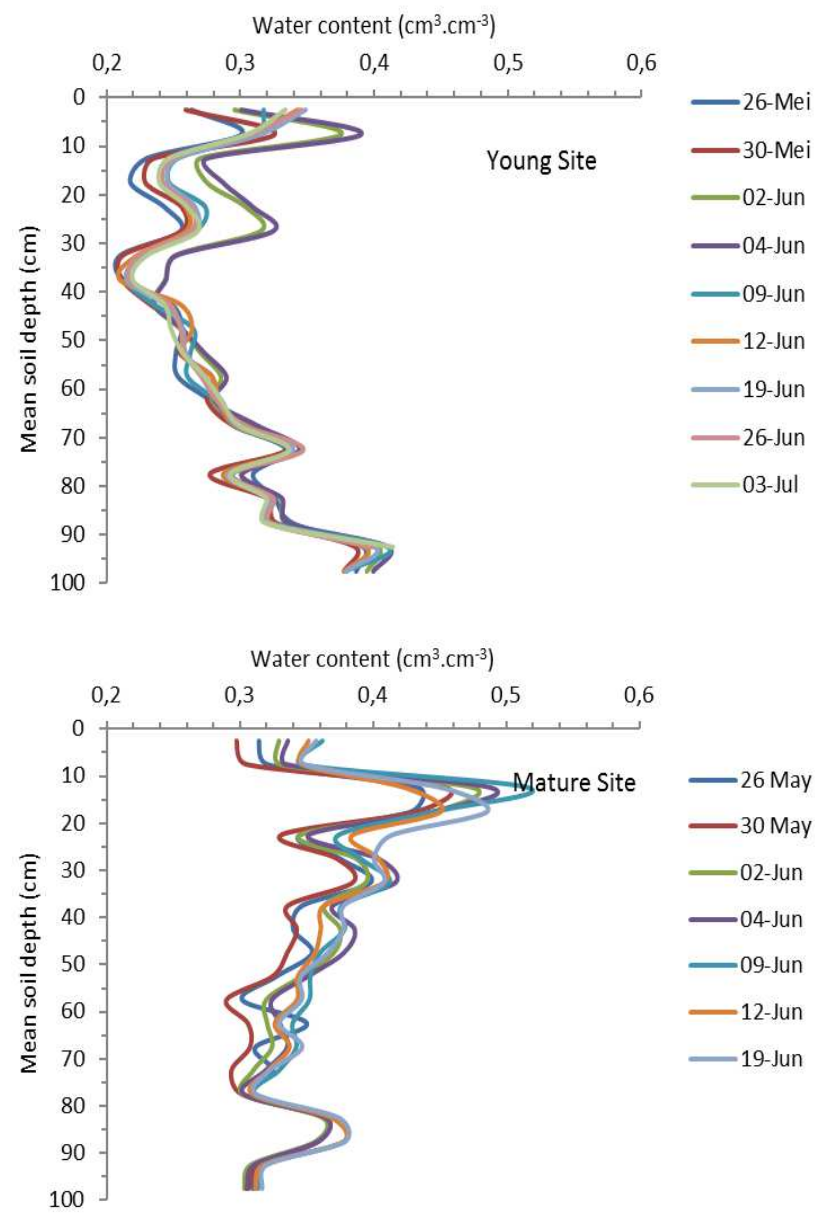

Fig. 6 The spatiotemporal variations in soil volumetric water content in two study sites.

Figure 6 showed both spatial and temporal (spatiotemporal) variations in soil volumetric water content in the two study sites. Overall volumetric water content profiles were higher under mature oil palm, ranging from 0.3 to $0.5 \mathrm{~cm}^{3} \cdot \mathrm{cm}^{-3}$ compared to 0.2 to $0.4 \mathrm{~cm}^{3} \cdot \mathrm{cm}^{-3}$ under young oil palm soils. Clay textured soil seemed to be the reason for higher volumetric soil water content at the mature site compared to sandy loam and sand at the young oil palm plantation. Clayed soils had higher bulk density than sandy layers; therefore, it resulted in higher volumetric water when multiplied with gravimetric water. On the other hand, soil layers at the mature oil palm plantation were dominated by micropores capable of holding more water against water releasing processes such as evaporation and percolation from the soil profile. On the other hand, Sandy soils were dominated by macropores that released water easier from each layer in the soil profile at the young oil palm site.

As found in this study, spatiotemporal variations in soil moisture can explain many aspects of soil and water management in agricultural land. When a map of soil physical characteristics is available in such an area, then typical spatiotemporal variation in soil water content may be used to estimate soil water balance throughout the year. For example, the spatial and monthly distribution of drought potential in the mapped area can be estimated based on the number of days without rainfall [30]. The rainfall-based information for drought distribution prediction will help growers and decision-makers manage crop cultivation during the dry season, particularly around the study region. Similarly, watershed integration rather than separate watersheds was more accurate in predicting potential drought distribution and improving water supply needs as a part of irrigation practices [31]. Agronomists and planters can also use the drought distribution information to develop drought-tolerant varieties to sustain crop productivity in such a region during the dry season [32]. Overall, this study offered a wide range of practical applications to develop a precise agriculture system, particularly concerning soil water.

In the future, the technique of real-time monitoring in soil wetness in agricultural land used in the current study can be upgraded for automatic recording. The future studies would focus on establishing Agriculture 4.0, referring mainly on interconnectivity, automation, machine learning, and realtime data. The dielectric device used in the current study read the impedance data, displayed them on the instrument's LED screen, stored them in a memory card, or sent them to the internet network. By integrating the dielectric instrument with the internet of things, the impedance data can be transmitted to the internet networks and read instantly from computers and smartphones. The technology can be useful in water-related land management in agricultural practices. Growers and managers, for example, may control irrigation systems remotely from their fingers.

\section{CONCLUSION}

Spatiotemporal variations in soil water content profiles were significantly different between the three-year and twenty-year oil palm plantations. Vertical distributions in volumetric water content indicated that the $0-60 \mathrm{~cm}$ layers were dryer and the $60-100 \mathrm{~cm}$ depths were wetter at the sandy soil under the young plantation compared to the clay soil at the mature site. Temporal variations in volumetric water content were high at the $0-40 \mathrm{~cm}$ and $0-75 \mathrm{~cm}$ layers for young and mature sites, respectively. The vertical distribution of bulk density and soil texture could explain the spatiotemporal variability in water content profile. Looser 
sandy layers throughout the young oil palm soil profile might cause a higher proportion of drainage pores and result in less water content compared to denser clay layers under the mature oil palm.

\section{ACKNOWLEDGMENT}

We would like to thank Muhamad Faisal and Ade Novaria (undergraduate students at the University of Bengkulu) to assist in the field works. This research was fully funded by the Directorate of Research and Community Service, Ministry of Research, Technology, and the Higher Education Republic of Indonesia, Contract No: 165/SP2H/LT/DRPM/2019.

\section{REFERENCES}

[1] L.E. Muñoz-Villers, F. Holwerda, M.S. Alvarado-Barrientos, D.R Geissert, T.E. Dawson, "Reduced dry season transpiration is coupled with shallow soil water use in tropical montane forest trees," Oecologia, vol. 188 no. 1, pp 303-317, 2018.

[2] B.M Flohr, J.R. Hunt, J.A. Kirkegaard, B.S.T. Rheinheimer, L. Goward, J.R. Evans, M. Bullock, "Deep soil water-use determines the yield benefit of long-cycle wheat," Frontiers in Plant Science, vol. 11, pp 1-13, 2020.

[3] F. Faridani, A. Farid, H. Ansari, S. Manfreda, "A modified version of the SMAR model for estimating root-zone soil moisture from timeseries of surface soil moisture," Water $S A$, vol 43. no. 3, pp. 492-498, 2017.

[4] P. Matgen, S. Heitz, S. Hasenauer, C.Hissler, L. Broccal, H.H.G Savanije, "On the potential of MetOp ASCAT-derived soil wetness indices as a new aperture for hydrological monitoring and prediction: a field evaluation over Luxembourg," Hydrol. Process, vol. 26, no. 15, pp. 2346-2359, 2012.

[5] E. Wallor, A. Herrmann, J. Zeitz, "Hydraulic properties of drained and cultivated fen soils part II - Model-based evaluation of generated van Genuchten parameters using experimental field data," Geoderma vol. 319, pp. 208-218, 2018.

[6] M. Rashmi, V. Pandey, "Reference evapotranspiration (ETo) and crop water requirement (ETc) of wheat and maize in Gujarat," Journal of Agrometeorology, vol. 17 no.1, pp. 107-, Jun. 2015.

[7] A. Klute, Ed., Methods of Soil Analysis: Part I-Physical and Mineralogical Methods, 2nd ed., Madison, USA: ASA-SSSA. 1986, vol. 9.

[8] M. A. Dafalla; A. M. Al-Mahbashi; A. Almajed; M. Al-Shamrani, "Predicting soil-water characteristic curves of clayey sand soils using area computation," Mathematical Problems in Engineering (2020), pp. 1-9, 2020. DOI: 10.1155/2020/4548912.

[9] M.B. Duygu, Z. Akyürek, "Using cosmic-ray neutron probes in validating satellite soil moisture products and land surface models," Water, vol. 11, no. 7, p. 1362, 2019.

[10] B. Hermawan, "Monitoring soil water content by measuring electrical properties on corn land," Indonesian Journal of Agricultural Sciences, vol. 7 no.1, pp. 15-22, 2005.

[11] M.B. Duygu, Z. Akyürek, "Using cosmic-ray neutron probes in validating satellite soil moisture products and land surface models," Water, vol. 11, no. 7, p 1362, 2019.

[12] T.E. Franz, A. Wahbi, M. Vreugdenhil, G. Weltin, L. Heng, M. Oismueller, P. Strauss, G. Dercon, D. Desilets. "Using Cosmic-Ray Neutron Probes to monitor landscape scale soil water content in mixed land use agricultural systems," Applied and Environmental Soil Science (2016), doi: http://dx.doi.org/10.1155/2016/4323742.

[13] X. Tan, J. Wu, J. Huang, M. Wu, W. Zeng, Wenzhi, "Design of a new TDR probe to measure water content and electrical conductivity in highly saline soils," Journal of Soils \& Sediments: Protection, Risk Assessment, \& Remediation, vol. 18, no.3, pp. 1087-1099. 2018.

[14] C. Chen, X. Yan, Y. Ma, S. Yu, Q. Xu, D.A. Grantz, P. Schulze Lammers, Z. Wang, Y. Sun, Q. Cheng, "Monitoring near-surface soil water content using an innovative perforated cylinder coaxial dielectric sensor," Journal of Hydrology, vol. 573, pp.746-754, 2019.

[15] H.H. Tao, C. Donough, J. Gerendas, M. Hoffmann, A. Cahyo, H. Sugianto, R. Wandri, G.A. Rahim, M. Fisher, R. Rötter, K. Dittert, L.
Pardon, T. Oberthür, "Fertilizer management effects on oil palm yield and nutrient use efficiency on sandy soils with limited water supply in Central Kalimantan," Nutrient Cycling in Agroecosystems, vol. 112, no. 3, pp. 317-333, 2018.

[16] C. B. S. Teh, "Development and validation of an unsaturated soil water flow model for oil palm," Pertanika Journal of Tropical Agricultural Science, vol. 41, no. 2, pp. 787-800, May 2018.

[17] B. Hermawan, E. Suparjo, K.S. Hindarto, R. Silalahi, F. Barchia, "A Quick Dielectric Method to Determine Insitu Soil Water Content for Precision Water Use under Sustainable Agricultural Practices," International Journal of Advanced Science Engineering Information Technology, vol. 7, no. 3, pp. 910-915, May-June 2017.

[18] E. Z. Bean, R.G. Huffaker, K.W. Migliaccio, "Estimating field capacity from volumetric soil water content time series using automated processing algorithms," Vadose Zone J., vol. 17, no. 1, April 2018, doi:10.2136/vzj2018.04.0073.

[19] L. Maik, S. Schlüter, Hans-Jörg Vogel, D. Vetterlein, "Soil structure formation along an agricultural chronosequence," Geoderma, vol 350, pp. 61-72, September 2019.

[20] R. Naghdi, A. Solgi, E.R. Labelle, M. Nikooy, "Combined effects of soil texture and machine operating trail gradient on changes in forest soil physical properties during ground-based skidding," Pedosphere, vol. 30, no. 4, pp. 508-516, 2020.

[21] J. Pöhlitz, J. Rücknagel, S. Schlüter, Hans-Jörg Vogel, O. Christen, "Estimation of critical stress ranges to preserve soil functions for differently textured soils," Soil \& Tillage Research, vol. 200, 2020. DOI: $10.1016 /$ j.still.2020.104637.

[22] J. A. S. de Freitas, V.R. da Silva, F.B. da Luz, D.R. Kaiser, A.L. Zwirtes, "Soil carbon and physical-mechanical properties after successive applications of swine and poultry organic waste," Pesquisa Agropecuária Tropical, vol 48, no. 4, pp. 390-398, 2018.

[23] G. Singh, S. Anand, B. Lall, A. Srivastava, V. Singh, "A low-cost portable wireless multi-frequency electrical impedance tomography system," Arabian Journal for Science \& Engineering, vol. 44, no. 3, pp. 2305-2320, 2019.

[24] V.I. Bulavin, I.N. V'yunnik, A.V. Kramarenko, "Kinetic solvation and electrical conductance of proton in infinitely diluted solutions of hydrogen halides in primary alcohols and in water: influence of temperature and solvent," Journal of Molecular Liquids, vol. 242, pp.1296-1309, 2017.

[25] A. Bartnik, P. Tomalski, "Diurnal variations of the basic physicochemical characteristics of a small urban river - the sokołówka in łódź - a case study," Acta Scientiarum Polonorum: Formatio Circumiectus, vol. 17, no. 3, pp. 23-38, 2017.

[26] D. Bertermann, H. Schwarz, "Bulk density and water contentdependent electrical resistivity analyses of different soil classes on a laboratory scale," Environmental Earth Sciences, vol. 7, no. 16, pp. $570-583,2018$

[27] K. Noborio, T. Kubo, "Evaluating a dual-frequency-phase-shift soil moistureand electrical conductivity sensor," Paddy Water Environ vpl. 15 , pp. 573-579, 2017. DOI 10.1007/s10333-016-0574-7.

[28] B. Hermawan, "Determination of soil water content by measuring a dielectrical property: a laboratory experiment at various compaction levels," Indonesian Journal of Agricultural Sciences, vol. 6 no. 2, pp. 66-74, 2004.

[29] Y. Paillet, N. Cassagne, and J.-J. Brun, "Monitoring forest soil properties with electrical resistivity," Biol Fertil Soils, vol. 46, pp. $451-460,2010$

[30] W. Widiyatmoko, Sudibyakto, E. Nurjani, E.W. Safriani, "Spatialtemporal patterns of agricultural drought in upper Progo Watershed based on remote sensing and land physical characteristics," International Journal of Advanced Science Engineering Information Technology, vol. 9, no. 2, pp. 480-488, July 2019.

[31] D. Daoed, B. Rusman, B. Istijono, A. Hakam, M. Syukur, "Evaluation of drought vulnerability on watersheds in West Sumatera Province by using Cropwat-8 and GIS," International Journal of Advanced Science Engineering Information Technology, vol. 8, no. 6, pp. 2443-2449, 2018.

[32] R. Herawati, Masdar, D.W. Ganefianti, B. Hermawan, Alnopri, "Screening and identification of upland rice lines derived recurrent selection for drought tolerance," International Journal of Advanced Science Engineering Information Technology, vol. 7, no. 6, pp. 23232327, 2017. 